\title{
Frontobiparietal remodeling with or without a widening bridge for sagittal synostosis: comparison of 2 cohorts for aesthetic and functional outcome
}

\author{
Marie-Lise C. van Veelen, MD, ${ }^{1}$ Dalibor Mihajlović, MD, ${ }^{1}$ Ruben Dammers, MD, PhD, ${ }^{1}$ \\ Hester Lingsma, PhD, ${ }^{2}$ Leon N. A. van Adrichem, MD, PhD, ${ }^{3}$ and \\ Irene M. J. Mathijssen, MD, PhD 3
}

Departments of ${ }^{1}$ Neurosurgery, ${ }^{2}$ Public Health, and ${ }^{3}$ Plastic and Reconstructive Surgery and Hand Surgery, Erasmus University Medical Center Rotterdam, The Netherlands

\begin{abstract}
OBJECT Various techniques to correct sagittal synostosis have been described. The authors of this study assess the results of 2 techniques for late complete cranial remodeling and test the hypothesis that adding a widening bridge would improve outcome.

METHODS In this retrospective study, the authors evaluated patients with nonsyndromic sagittal synostosis-those who underwent frontobiparietal remodeling (FBR) and those who underwent modified FBR (MFBR) involving the introduction of a bony bridge to increase the width of the skull. Outcomes for both groups are described in terms of the aesthetic results assessed on photographs and any changes in the cranial index (Cl) and head circumference over time, the presence of papilledema, and complaints of headache. The effect of the surgical technique on $\mathrm{Cl}$ and head circumference over time was assessed using linear regression analysis, with adjustment for preoperative $\mathrm{Cl}$ and head circumference.

RESULTS Sixty-nine patients with isolated sagittal synostosis were included in this study: 35 underwent MFBR and 34 underwent the original technique of FBR. The mean follow-up period was 7 years. In the 1st year after surgery, mean $\mathrm{Cl}$ improved by $9 \%$ in the FBR group and by $12 \%$ in the MFBR group. One year after surgery, $\mathrm{Cl}$ in the MFBR group was on average $4.7 \%$ higher than that in the FBR group ( $p<0.001$ ). During follow-up, $\mathrm{Cl}$ decreased in both groups; however, at all time points $\mathrm{Cl}$ was significantly higher in the MFBR group than in the FBR group. The impact of surgical technique on $\mathrm{Cl}$ was less important than the impact of preoperative $\mathrm{Cl}\left(\mathrm{R}^{2}=0.26 \mathrm{vs} 0.54\right)$, and this applied at all time points during follow-up. Head circumference declined during follow-up in both groups. It was influenced by preoperative head circumference, but not by surgical technique. Aesthetic outcome, prevalence of headache (42\%), and papilledema (7\%) were comparable in both groups.
\end{abstract}

CONCLUSIONS Adding a widening bridge to late complete remodeling significantly improved $\mathrm{Cl}$ and helped to prevent $\mathrm{Cl}$ from decreasing in the long term. This addition did not affect the head circumference growth curve. Despite a mean head circumference remaining at $+1 \mathrm{SD}$, patients continued to develop papilledema postoperatively $(7 \%)$.

http://thejns.org/doi/abs/10.3171/2014.12.PEDS14260

KEY WORDS sagittal synostosis; surgery; outcome; craniofacial

$\mathrm{S}$ AGITTAL synostosis is the premature closure of the sagittal suture. The typical scaphocephalic skull shape results from restricted growth at the affected suture and compensatory growth at the patent sutures. Although sagittal synostosis is mainly considered to be a cosmetic problem, variable incidences of increased intracranial pressure (ICP) and mild cognitive disturbances have been described despite treatment.
Over 20 different techniques to correct sagittal synostosis have been described. $3,5,9-12,15,17,20-23,26-31,33-36,38,40,43-51$ The field continues to evolve and aims to reduce the impact of surgery. Minimally invasive approaches constitute the majority of recently detailed techniques. ${ }^{9,20,28,38,40,44,53}$ However, complete remodeling at a later age remains relevant since some patients will continue to present late and several centers still prefer to perform total remodeling at a later

ABBREVIATIONS $\mathrm{Cl}=$ cranial index; FBR = frontobiparietal remodeling; $\mathrm{HC}=$ head circumference; $\mathrm{HCSD}=\mathrm{HC}$ in standard deviation; ICP = intracranial pressure; $\mathrm{MFBR}$ = modified FBR.

SUBMITTED June 3, 2014. ACCEPTED December 19, 2014.

INCLUDE WHEN CITING Published online April 24, 2015; DOI: 10.3171/2014.12.PEDS14260.

DISCLOSURE The authors report no conflict of interest concerning the materials or methods used in this study or the findings specified in this paper. 
age. The latter was verified by US and worldwide surveys of currently used techniques. In these surveys the majority of centers still performed total remodeling: $61 \%$ and $66 \%$, respectively, according to data presented at the International Society of Craniofacial Surgery Biennial Congress $2011^{42}$ and the European Society of Craniofacial Surgery Biennial Congress 2012.13 Apparently, centers are satisfied with their results and remain reluctant to adopt newer techniques given that long-term results are still unknown.

Long-term outcome is still a concern. Aesthetic results tend to decrease over time, as shown in several studies. ${ }^{2,15,16}$ This phenomenon seems to occur regardless of the timing and extensiveness of the surgical correction. Moreover, the risk of developing increased ICP remains after remodeling. ${ }^{1,7,8,37,52}$ The incidence of raised ICP in untreated patients is reported to be as high as $10 \%-20 \%{ }^{8,25}$ After surgery, the incidence decreases but remains at around $1 \%-9 \%$. At our institution we hypothesized that long-term aesthetic results and cranial volume would increase by adding a widening bridge to the conventional frontobiparietal remodeling (FBR) by taking the sagittal strip, rotating it $90^{\circ}$, and fixating it between the parietal flaps. This complete remodeling is performed "late" (after 9 months of age) and is reserved for children who present to our institution after the age of 6 months. To validate our hypothesis, we compared the outcomes of 2 cohorts of patients, that is, those who underwent FBR either with or without adding the widening bridge.

\section{Methods}

This study includes patients diagnosed with nonsyndromic sagittal synostosis. Exclusion criteria were familial cases of scaphocephaly, having had surgery performed elsewhere, and a follow-up of $\leq 1$ year.

At our center, according to our treatment algorithm, patients presenting before the age of 6 months undergo early extended strip craniotomy. Patients presenting after 6 months of age undergo complete cranial remodeling between 9 and 12 months of age. This study covers the patients who underwent complete remodeling. All children underwent surgery at Sophia's Children's Hospital in Rotterdam. Data were retrospectively extracted from the patient medical records. Follow-up data were collected until the 1st of January 2011.

Roddi, Vaandrager, and colleagues described the gore pattern technique in 1993. ${ }^{47}$ The modification of adding a widening bridge to biparietal remodeling with the gore pattern technique was introduced in 1999. Between 1999 and 2006, 35 consecutive patients at our institute underwent this modified technique. To create 2 equal groups, moving backward in time until 1991, we identified 34 consecutive patients who had undergone the original technique.

According to our protocol, a skull radiograph and CT were preoperatively obtained for each patient. Head circumference (HC) measurements, fundoscopy, standardized photos, and skull radiographs were obtained pre- and postoperatively at regular intervals. Information on complaints of headache was noted in the patient charts. At the postoperative follow-up, the surgeon graded the results as "good" in the case of no or slight residual signs of the primary abnormality; "acceptable" in the case of visible residual abnormality, such as frontal bossing, supraorbital narrowing, or occipital protuberance; and "unacceptable" in the case of an important and cosmetically disturbing abnormality in the head shape. In a blinded fashion, 2 independent surgeons scored on a 3-point scale any postoperative frontal bossing and temporal narrowing on standardized photographs. Other stigmata of scaphocephaly, such as low vertex and occipital bulleting, were not scored on the photographs because, in most cases, the hair concealed these signs.

The cranial index (CI) was calculated on skull radiographs by dividing the maximal length over the maximal width of the skull. Head circumference was recalculated into standard deviation by using the software from Growth Analyzer (Growth Analyzer B.V.).

The 2 surgical techniques performed in the patients were the FBR and the modified FBR (MFBR). The FBR consists of the creation of a sagittal strip, a frontal flap, and 2 parietal flaps (Fig. 1A-D). The frontal flap is shortened at its caudal edge and tilted backward (Fig. 1E). Both parietal flaps are remodeled using the gore pattern technique and replaced with a slight overlap over the temporal bone (Fig. 2A and B). The modification (Fig. 2C and D) consists of replacing the sagittal strip, which is rotated $90^{\circ}$, cut to the desired length, and fixed between both parietal flaps. The length of the strip is taken as the maximum that still allows closure of the skin without too much tension.

Data were analyzed using SPSS 19 (IBM Corp.). To compare the $\mathrm{CI}$ and $\mathrm{HC}$ between techniques and at different time points, we used the Mann-Whitney U-test. The occurrence of adverse events, such as headache and papilledema, was analyzed with Fisher's exact test. The effect of the surgical technique and preoperative CI on the postoperative CI was evaluated by univariable and multivariable regression analysis, as was the effect of the surgical technique and preoperative $\mathrm{HC}$ on postoperative HC. From these models, betas and corresponding $\mathrm{p}$ values were reported to quantify the effect of the independent variables on outcome. In addition, the coefficient of determination $\left(\mathrm{R}^{2}\right)$ was reported as a measure of how much variance in outcome was explained by the surgical technique versus the preoperative characteristics. The correlation between the different outcome measures and age at surgery was explored with Pearson correlation coefficients.

\section{Results}

Sixty-nine children with isolated sagittal synostosis were included in this study: 34 underwent FBR and 35 underwent MFBR. The mean age at surgery was 11.3 months (range 5.0-18.0 months), and there were no significant differences between the 2 cohorts. Other patient characteristics are presented in Table 1. The mean follow-up was 7 years (range $1-16$ years, SD 4.7 years).

The length of the operations was nearly 3 hours, with no significant difference between the 2 techniques. The difference in blood loss between the 2 procedures was attributable to 1 patient, who had undergone surgery in 1994, suffered a sagittal sinus tear, and lost $7000 \mathrm{ml}$ of 

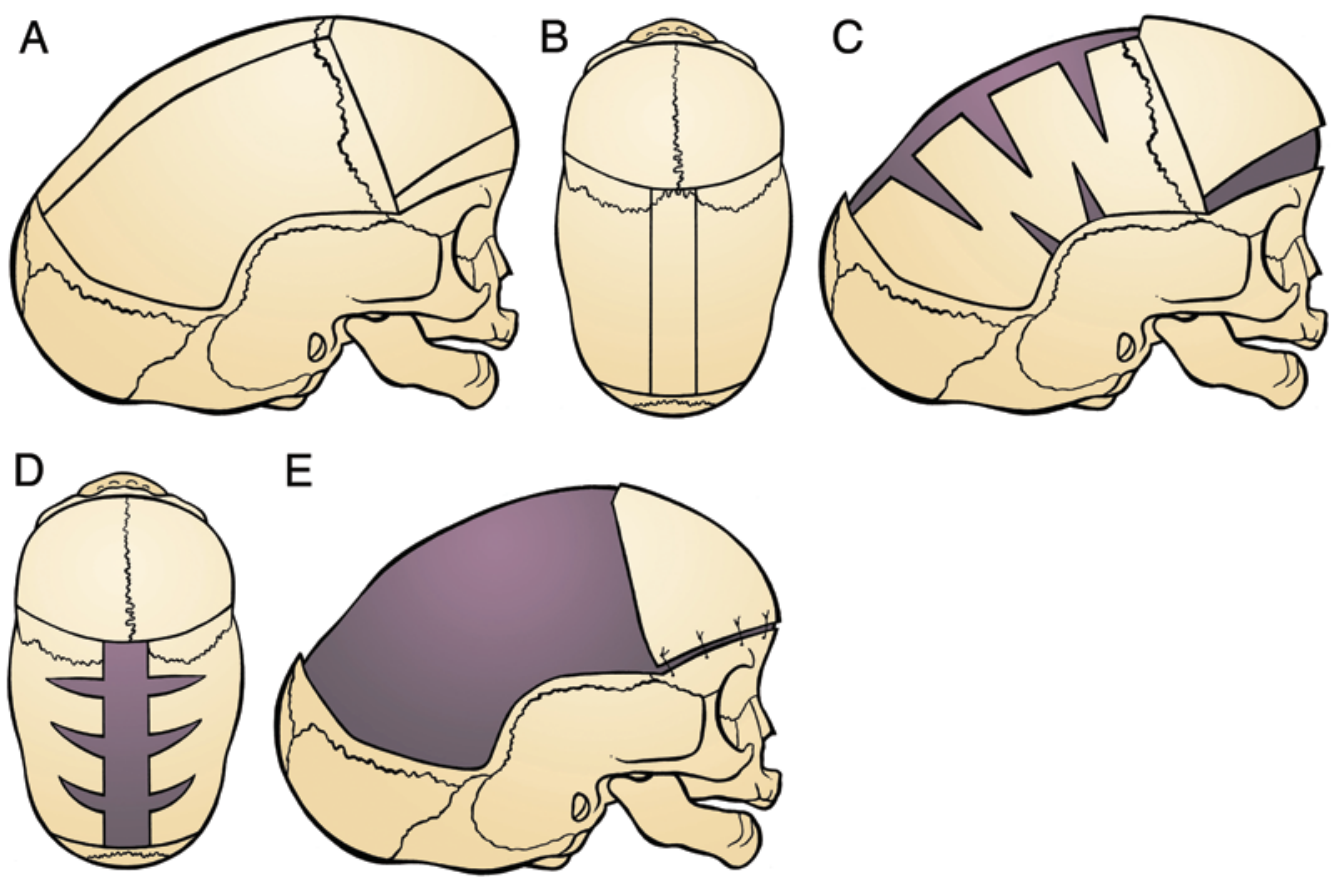

FIG. 1. A-D: Craniotomy lines. E: Frontal repositioning. Copyright M. L. C. van Veelen. Published with permission. Figure is available in color online only.

blood. Dural defects occurred in 8 patients, but none of them resulted in a CSF leak postoperatively.

Surgeons scored a good result in $74 \%$ of cases, acceptable in $23 \%$, and unacceptable in $3 \%$; these scores were similar in both groups. Photographs were obtained in 56 of the 69 patients. Scores for frontal bossing and temporal narrowing are presented in Table 2. Residual bossing
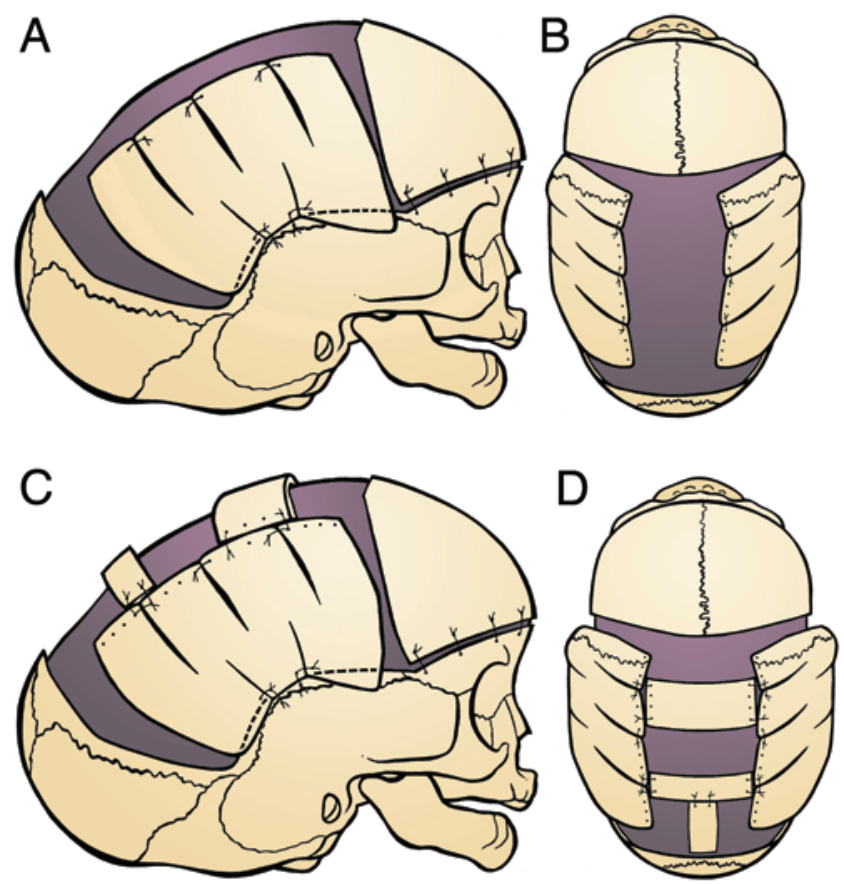

FIG. 2. A and B: Original reconstruction. C and D: Modified reconstruction. Copyright M. L. C. van Veelen. Published with permission. Figure is available in color online only. was seen in $38 \%$ of patients and supraorbital narrowing in $62 \%$. Frontal bossing became less visible with age; after 8 years of age, $84 \%$ had no visible bossing. Supraorbital narrowing occurred more frequently after the conventional than after the modified technique. One patient underwent secondary correction of the supraorbital narrowing. Further analysis of excessive supraorbital narrowing failed to reveal an underlying factor; temporal narrowing was not related to CI, age at surgery, or the extent of the correction of frontal bossing.

Preoperative and postoperative CIs are listed in Table 3 and graphed in Fig. 3. Preoperative CI was 64 (range 59.1-69.0, SD 2.9) in patients undergoing FBR and 67 (range 62.0-76.9, SD 4.3) in those undergoing MFBR. Postoperative (12-24 months) CI increased by $9 \%$ to become 70.3 (range 63.9-77.4, SD 4.0) in the FBR group and by $12 \%$ to become 75.1 (range 65.9-84.4, SD 4.1) in the MFBR group. Both techniques showed a decrease in CI during subsequent years. This decrease at 37-48 months postoperatively was greater after FBR than after MFBR: 67 (62-73, SD 4.7) and 74 (64-80, SD 3.9), respectively. Regression analysis (Table 4) showed that CI in the MFBR group was, on average, $4.7 \%$ higher than that in the FBR group after $12-24$ months ( $p<0.001)$ and, on average, $6.6 \%$ higher after $37-48$ months $(\mathrm{p}=0.001)$ postoperatively. The effect was less pronounced at 24-36 months after surgery $(\beta=3.5 \%, \mathrm{p}=0.036)$.

Because CI has a tendency to decline over the years, we were interested to see if the influence of surgery on postoperative CI would diminish over the years as compared with the influence of preoperative CI. In other words, would the natural tendency of the skull growth eventually win over surgery? Multivariable regression analysis showed that the surgical technique had less impact on 
TABLE 1. Summary of characteristics and surgical details in 69 patients with nonsyndromic sagittal synostosis treated with FBR or MFBR

\begin{tabular}{|c|c|c|c|c|}
\hline Parameter & No. of Patients Evaluated & Entire Study Cohort & FBR Group & MFBR Group \\
\hline Total & 69 & 69 & 34 & 35 \\
\hline $\operatorname{Sex}(\%)$ & 69 & & & \\
\hline Male & & $57(83)$ & 31 & 26 \\
\hline Female & & $12(17)$ & 3 & 9 \\
\hline Preop Cl per radiography (SD) & 55 & $66(3.9)$ & $64(2.9)$ & $67(4.3)$ \\
\hline Preop Cl per CT (SD) & 68 & $64(4.8)$ & $63(3.5)$ & $65(5.8)$ \\
\hline Mean age at op in mos (range) & 69 & $11.3(5-18)$ & $11.5(5-18)$ & $11.2(8-15)$ \\
\hline Mean length of op in min (range) & 62 & $181(105-300)$ & $168(105-290)$ & $191(136-300)$ \\
\hline Mean blood loss in ml (range) & 63 & $1042(300-7000)$ & $1174(400-7000$ & $914(300-2220)$ \\
\hline \multicolumn{5}{|l|}{ Complications } \\
\hline Dural defect & & 8 & 5 & 3 \\
\hline Sagittal sinus bleeding & & 1 & 1 & 0 \\
\hline CSF leakage & & 0 & 0 & 0 \\
\hline Postop hemorrhage & & 1 & 0 & 1 \\
\hline
\end{tabular}

postoperative $\mathrm{CI}$ than the preoperative $\mathrm{CI}$ had on postoperative $\mathrm{CI}$ at all time points $\left(\mathrm{R}^{2}\right.$ surgical technique $0.15-$ $0.38, \mathrm{R}^{2}$ preoperative CI 0.47-0.57; Table 4). For example, a $1 \%$ increase in preoperative CI was associated with a $0.7 \%$ increase in CI at 12-24 months (adjusted for surgical technique). However, the effect of surgery remained stable throughout the entire follow-up period.
The mean $\mathrm{HC}$ of patients, expressed as $\mathrm{HC}$ in $\mathrm{SD}$ (HCSD), was 1.7 preoperatively. During the 1st year after surgery, an initial increase in the SD of the HC was observed in both groups combined, which was followed by a decrease in the subsequent postoperative periods to a mean SD of 0.88 at 3-4 years after surgery (Table 3 and Fig. 4). The HC was lower for MFBR compared with FBR

TABLE 2. Surgical outcome and follow-up in 69 patients treated with FBR or MFBR

\begin{tabular}{|c|c|c|c|c|}
\hline Parameter & No. of Patients Evaluated & Entire Cohort & FBR Group & MFBR Group \\
\hline Surgeon score & 65 & & & \\
\hline Good & & $48(74 \%)$ & 24 & 24 \\
\hline Acceptable & & $15(23 \%)$ & 7 & 8 \\
\hline Unacceptable & & $2(3 \%)$ & 0 & 2 \\
\hline Photograph score & 56 & & & \\
\hline \multicolumn{5}{|l|}{ Frontal bossing } \\
\hline 0 & & $35(62 \%)$ & $13(57 \%)$ & $22(67 \%)$ \\
\hline 1 & & $20(30 \%)$ & $10(44 \%)$ & $10(30 \%)$ \\
\hline 2 & & $1(2 \%)$ & $0(0 \%)$ & $1(3 \%)$ \\
\hline \multicolumn{5}{|l|}{ Supraorbital narrowing } \\
\hline 0 & & $21(38 \%)$ & $4(17 \%)$ & $16(50 \%)$ \\
\hline 1 & & $32(57 \%)$ & $17(74 \%)$ & $15(47 \%)$ \\
\hline 2 & & $3(5 \%)$ & $2(9 \%)$ & $1(3 \%)$ \\
\hline Reoperation & 69 & & & \\
\hline Increased ICP & & $3(4.4 \%)$ & 1 & 2 \\
\hline Irregular skull shape & & 1 & 1 & 0 \\
\hline \multicolumn{5}{|l|}{ Papilledema } \\
\hline Preop & 58 & 6 & $3(12 \%)$ & $3(9 \%)$ \\
\hline Postop & 44 & 3 & $1(6 \%)$ & $2(7 \%)$ \\
\hline Headache & 57 & & & \\
\hline No & & $33(58 \%)$ & 16 & 17 \\
\hline Occasionally & & $18(32 \%)$ & 7 & 11 \\
\hline Frequently & & $6(10 \%)$ & 4 & 2 \\
\hline
\end{tabular}


TABLE 3. Cranial index and HCSD

\begin{tabular}{lcccc}
\hline \multicolumn{1}{c}{ Parameter } & No. of Patients Evaluated & Entire Study Cohort (SD) & FBR (SD) & MFBR (SD) \\
\hline Total & & 69 & 34 & 35 \\
\hline Mean preop Cl & 55 & $66.0(3.9)$ & $64.0(2.9)$ & $67.0(4.3)$ \\
\hline Mean postop Cl & & & & \\
\hline 12-24 mos & 50 & $73.0(4.7)$ & $70.3(4.0)$ & $75.1(4.1)$ \\
\hline 25-36 mos & 29 & $71.7(4.5)$ & $69.9(4.0)$ & $73.5(4.4)$ \\
\hline 37-48 mos & 29 & $71.1(5.2)$ & $67.0(4.7)$ & $73.6(3.9)$ \\
\hline Mean preop HCSD & 58 & $1.7(1.1)$ & $2.0(1.2)$ & $1.5(1.0)$ \\
\hline Mean postop HCSD & & & & 1.0 \\
\hline 12-24 mos & 47 & $1.8(1.1)$ & $2.0(1.3)$ & $1.7(1.0)$ \\
\hline $25-36$ mos & 40 & $1.6(1.0)$ & $1.9(1.2)$ & $1.3(0.8)$ \\
\hline $37-48$ mos & 38 & $1.0(1.1)$ & $1.2(1.3)$ & $0.8(0.9)$ \\
\hline $49-60$ mos & 27 & $0.9(1.1)$ & $1.1(1.5)$ & $0.8(0.9)$ \\
\hline
\end{tabular}

at all time points, but the differences were not significant. Postoperative $\mathrm{HC}$ was mainly influenced by preoperative $\mathrm{HC}\left(\mathrm{R}^{2} 0.41-0.59\right)$. For example, a $1 \mathrm{SD}$ increase in preoperative $\mathrm{HC}$ was associated with a $0.64 \mathrm{SD}$ increase in $\mathrm{HC}$ at $12-24$ months. This effect remained throughout the entire follow-up (Table 5).

For both techniques, papilledema and headache occurred with a similar frequency (Table 2). This result was confirmed by statistical analysis $(\mathrm{p}=0.1$ and 0.8 , respectively).

Papilledema occurred before surgery in $10.3 \%$ of 58 patients. After surgery, papilledema was observed in 3 (7\%) of 44 examined patients, ages 3.5, 4, and 6 years. All had stagnating skull growth: mean decline of HCSD -1.5 , compared with -0.7 in the whole group. The CI was normal (mean 78 [range 73-83]). Two patients had additional 24-hour ICP monitoring, which confirmed the suspicion of increased ICP. All 3 of these patients underwent reoperation.

In the charts of 57 patients, information was available on the occurrence of headache; $42 \%$ of them complained of headache. In $32 \%$, headache occurred occasionally;

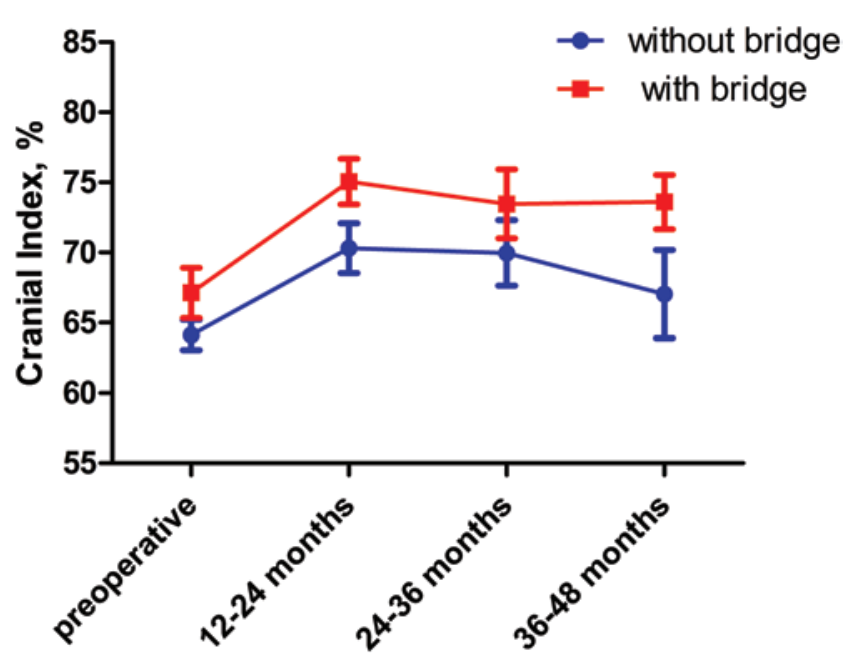

FIG. 3. Cranial index before and after surgery for FBR and MFBR. Figure is available in color online only. in $10 \%$, headache occurred frequently. The mean age at which headache complaints were reported was 5.6 years (range 2-12 years, SD 2.9).

\section{Discussion}

In this study, the modified technique was comparable to the original with respect to duration of surgery, blood loss, and complications. The surgeon's score, in contrast to the CI, revealed no significant difference between the 2 patient groups. The surgeon's judgment of the operative result is frequently used to assess outcome; however, grading by the surgeon is subjective and may not be sufficiently discriminative. ${ }^{41,54}$ Cranial index continues to be the most commonly used measure. Because it discriminates between normal and abnormal values ${ }^{14,24}$ and is objective, reliable, and simple to assess, CI seems to be a robust outcome measure.

The photographic score also showed no difference between the 2 surgical techniques, perhaps because the score only addresses the forehead. It is noteworthy that, after the age of 8 years, frontal bossing had disappeared in almost

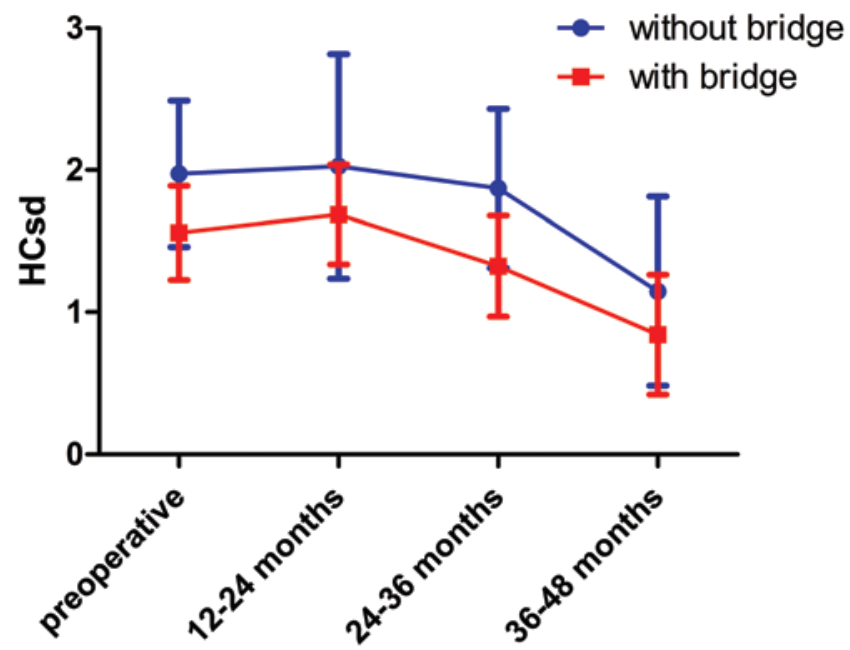

FIG. 4. Head circumference in standard deviation before and after MFBR. Figure is available in color online only. 
TABLE 4. Effect of surgical technique and preoperative $\mathrm{Cl}$ on postoperative $\mathrm{Cl}$

\begin{tabular}{|c|c|c|c|c|c|c|c|c|}
\hline \multirow[b]{2}{*}{ Factor } & \multicolumn{4}{|c|}{ Univariable Regression } & \multicolumn{4}{|c|}{ Multivariable Regression } \\
\hline & No. & $\beta(\%)$ & $p$ & $\mathrm{R}^{2}$ & No. & $\beta(\%)$ & $p$ & $\mathrm{R}^{2}$ \\
\hline \multicolumn{9}{|l|}{$\mathrm{Cl} 12-24 \mathrm{mos}$} \\
\hline Technique (MFBR) & 50 & 4.7 & 0.000 & 0.26 & 43 & 3.5 & 0.001 & 0.63 \\
\hline Preop Cl (per \% increase) & 43 & 0.85 & 0.000 & 0.540 & 43 & 0.70 & 0.000 & \\
\hline \multicolumn{9}{|l|}{$\mathrm{Cl} 25-36 \mathrm{mos}$} \\
\hline Technique (MFBR) & 29 & 3.5 & 0.036 & 0.15 & 24 & 0.99 & 0.502 & 0.58 \\
\hline Preop Cl (per \% increase) & 24 & 0.84 & 0.000 & 0.57 & 24 & 0.79 & 0.000 & \\
\hline \multicolumn{9}{|l|}{ Cl 37-48 mos } \\
\hline Technique (MFBR) & 29 & 6.6 & 0.000 & 0.38 & 26 & 5.3 & 0.001 & 0.66 \\
\hline Preop Cl (per \% increase) & 26 & 1.0 & 0.000 & 0.47 & 26 & 0.75 & 0.001 & \\
\hline
\end{tabular}

all patients. Khechoyan et al. ${ }^{32}$ demonstrated spontaneous correction of the frontal bossing in patients surgically treated at a mean age of 6 months. Our finding suggests that, with surgery at a later age, excessive correction of frontal bossing is unnecessary.

Introducing the widening bridge improved CI, not only immediately after surgery but also longer term. The initial postoperative CI of 75 or the 2- to 4-year postoperative CI of 73 was a good result, as compared with others. ${ }^{2,4,6,12}$, 15,18,22,23,29-32,36,39,40,46,51 The decrease in CI that we observed over time is comparable to the limited available data on long-term outcome. ${ }^{2,16}$ Adding a widening bridge complies with Fearon and colleagues' suggestion to overcorrect width to compensate for later growth restriction in that direction.

The present study has both strengths and limitations. Although it does have a relatively long mean time to follow-up, because of some loss to follow-up, our analysis of long-term outcome is somewhat less reliable. However, as all of our results were consistent over time, we believe that no bias occurred as a result of that loss to follow-up. Studying the effect of treatment on nonrandomized data carries the risk of confounding by indication. In our study the treatment decision (MFBR vs FBR) was not based on patient characteristics but simply on a change that occurred over time, which is reflected in the comparability of the 2 groups in terms of baseline characteristics. Additionally, we adjusted for preoperative $\mathrm{CI}$ and $\mathrm{HC}$.

It is interesting that preoperative CI had a greater im- pact on postoperative CI than surgery. However, in contrast to what we expected, the effect of surgery does not decrease during follow-up.

Surprisingly, the surgical technique improved CI but not $\mathrm{HC}$, perhaps because of the increased rotundity. Defining the ideal postoperative $\mathrm{HC}$ remains difficult since preoperative $\mathrm{HC}, \mathrm{CI}$, and the potential for normal and compensatory growth influenced it. A postoperative decrease in $\mathrm{HC}$ to a level still larger than that in the normal population has been reported..$^{15,51}$ In the present study, HC was overcorrected since it increased from larger than normal before surgery to even larger after surgery. In the 2-3 years after surgery, $\mathrm{HC}$ decreased and stabilized around $0.88 \mathrm{SD}$. This means that the timing and extent of surgery can influence cranial volume for about 2-3 years postsurgery. The impact of this difference is unknown but may be important since it occurs in a period with the most extensive cerebral growth.

Papilledema occurred after surgery at the age of around 4-6 years in 7\% of the examined patients; however, only 44 of the 69 patients were examined. It is very likely that patients with complaints were examined and that patients without any risk factors were not. Calculating the percentage over the entire study population brings the percentage down to $4 \%$. However, either percentage remains high compared with those reported by others..$^{1,7}$

In our patients, headache was reported relatively frequently: in 24 (42\%) of 57. However, compared with its prevalence in the normal pediatric population, this per-

TABLE 5. Regression analysis for HCSD

\begin{tabular}{|c|c|c|c|c|c|c|c|c|}
\hline \multirow[b]{2}{*}{ Factor } & \multicolumn{4}{|c|}{ Univariable Regression } & \multicolumn{4}{|c|}{ Multivariable Regression } \\
\hline & No. & $\beta$ & $p$ & $\mathrm{R}^{2}$ & No. & $\beta$ & $p$ & $\mathrm{R}^{2}$ \\
\hline \multicolumn{9}{|l|}{ HCSD 12-24 mos } \\
\hline Technique (MFBR) & 47 & -0.38 & 0.296 & 0.02 & 46 & 0.00 & 0.996 & 0.41 \\
\hline Preop HCSD (per SD increase) & 46 & 0.64 & 0.000 & 0.41 & 46 & 0.64 & 0.000 & \\
\hline \multicolumn{9}{|l|}{ HCSD $25-36$ mos } \\
\hline Technique (MFBR) & 39 & -0.55 & 0.086 & 0.08 & 35 & -0.39 & 0.164 & 0.45 \\
\hline Preop HCSD (per SD increase) & 35 & 0.60 & 0.000 & 0.42 & 35 & 0.50 & 0.001 & \\
\hline \multicolumn{9}{|l|}{ HCSD $37-48$ mos } \\
\hline Technique (MFBR) & 38 & -0.36 & 0.329 & 0.03 & 35 & -0.41 & 0.092 & 0.63 \\
\hline Preop HCSD (per SD increase) & 35 & 0.674 & 0.000 & 0.59 & 35 & 0.64 & 0.000 & \\
\hline
\end{tabular}


centage is not particularly high. In the general population, $25 \%$ of children report incidental headache by the age of 5 years. In 7- to 9-year-old children, $47.2 \%$ have experienced headache. ${ }^{19}$ Our data show that headache is a frequent complaint after surgery for sagittal synostosis, but its prevalence does not exceed that in the normal population.

We have shown that surgical correction influences $\mathrm{HC}$ until the age of 3-4 years. It is remarkable that papilledema and headache start to occur immediately after this period. Sagittal synostosis carries a larger risk for developing papilledema and elevated ICP, both before and after surgery, than other unisutural synostosis. One may speculate on the origin of this finding. The suture is longer than the others and therefore may have more impact on skull growth. Moreover, the synostosis occurs at the level of sagittal sinus where the synostosis may compromise venous drainage or the functioning of arachnoid villi. Further research on these pathophysiological mechanisms may help to find (surgical) techniques that prevent increased ICP in these children.

What is the impact of the findings in this study given the increasing popularity of minimally invasive and endoscope-assisted correction of sagittal synostosis? Minimally invasive techniques are a valuable improvement in the procedures to correct sagittal synostosis. However, these techniques have better results with decreasing age at surgery, preferably around 3 months of age..$^{44,46}$ Not all patients are referred soon enough to undergo such early interventions; for those patients, late remodeling remains a reality. Furthermore, long-term results on minimally invasive procedures are scarce, and data on the incidence of elevated ICP and papilledema are lacking. The high incidence of papilledema in the present study demonstrates that detailed long-term follow-up is necessary to establish the safety of minimally invasive procedures in the long term.

The large and increasing number of techniques to correct sagittal synostosis necessitates the definition of outcome parameters that adequately reflect surgical results. A set of both functional and cosmetic measures is indicated, in which craniocephalic measurements, such as CI, and clinical and patient-reported grading systems are complementary.

\section{Conclusions}

Introducing a widening bridge to FBR remodeling performed at 9-12 months of age results in a significantly higher postoperative CI. Although CI decreases on longer follow-up, the positive effect of adding a bridge remains significant in the long term (37-48 months postoperatively). Therefore, we recommend the addition of a widening bridge to FBR for sagittal synostosis when surgery is performed after the age of 9 months.

\section{References}

1. Adamo MA, Pollack IF: A single-center experience with symptomatic postoperative calvarial growth restriction after extended strip craniectomy for sagittal craniosynostosis. J Neurosurg Pediatr 5:131-135, 2010

2. Agrawal D, Steinbok P, Cochrane DD: Long-term anthropometric outcomes following surgery for isolated sagittal craniosynostosis. J Neurosurg 105 (5 Suppl):357-360, 2006
3. Albright AL: Operative normalization of skull shape in sagittal synostosis. Neurosurgery 17:329-331, 1985

4. Alvarez-Garijo JA, Cavadas PC, Vila MM, Alvarez-Llanas A: Sagittal synostosis: results of surgical treatment in 210 patients. Childs Nerv Syst 17:64-68, 2001

5. Anderson FM, Johnson FL: Craniosynostosis; a modification in surgical treatment. Surgery 40:961-970, 1956

6. Antúnez S, Arnaud E, Cruz A, Marchac D, Renier D: Scaphocephaly: Part I: indices for scaphocephalic frontal and occipital morphology evaluation: long-term results. J Craniofac Surg 20 (Suppl 2):1837-1842, 2009

7. Arnaud E, Capon-Degardin N, Michienzi J, Di Rocco F, Renier D: Scaphocephaly part II: Secondary coronal synostosis after scaphocephalic surgical correction. J Craniofac Surg 20 (Suppl 2): 1843-1850, 2009

8. Arnaud E, Renier D, Marchac D: Prognosis for mental function in scaphocephaly. J Neurosurg 83:476-479, 1995

9. Barone CM, Jimenez DF: Endoscopic approach to coronal craniosynostosis. Clin Plast Surg 31:415-422, vi, 2004

10. Boop FA, Chadduck WM, Shewmake K, Teo C: Outcome analysis of 85 patients undergoing the pi procedure for correction of sagittal synostosis. J Neurosurg 85:50-55, 1996

11. Boulos PT, Lin KY, Jane JA Jr, Jane JA Sr: Correction of sagittal synostosis using a modified Pi method. Clin Plast Surg 31:489-498, vii, 2004

12. David LR, Plikaitis CM, Couture D, Glazier SS, Argenta LC: Outcome analysis of our first 75 spring-assisted surgeries for scaphocephaly. J Craniofac Surg 21:3-9, 2010

13. Di Rocco F, Ben Gbulie U, Meyer P, Arnaud E: Current techniques and protocols in the surgical management of scaphocephaly in young infants. J Craniofac Surg 25:39-41, 2014

14. Farkas LG, Hreczko TM, Katic MJ, Forrest CR: Proportion indices in the craniofacial regions of 284 healthy North American white children between 1 and 5 years of age. $\mathbf{J}$ Craniofac Surg 14:13-28, 2003

15. Fearon JA, McLaughlin EB, Kolar JC: Sagittal craniosynostosis: surgical outcomes and long-term growth. Plast Reconstr Surg 117:532-541, 2006

16. Fearon JA, Ruotolo RA, Kolar JC: Single sutural craniosynostoses: surgical outcomes and long-term growth. Plast Reconstr Surg 123:635-642, 2009

17. Fowler FD, Ingraham FD: A new method for applying polyethylene film to the skull in the treatment of craniosynostosis. J Neurosurg 14:584-586, 1957

18. Friede H, Lauritzen C, Figueroa AA: Roentgencephalometric follow-up after early osteotomies in patients with scaphocephaly. J Craniofac Surg 7:96-101, 1996

19. Gallelli L, Iannacchero R, Cannistra U, La Vitola A, Peltrone F, De Caro E, et al: Headache prevalence and treatments in secondary school populations of Catanzaro: a questionnairebased study. Cephalalgia 24:800, 2004

20. Gociman B, Marengo J, Ying J, Kestle JR, Siddiqi F: Minimally invasive strip craniectomy for sagittal synostosis. J Craniofac Surg 23:825-828, 2012

21. Greene CS Jr, Winston KR: Treatment of scaphocephaly with sagittal craniectomy and biparietal morcellation. Neurosurgery 23:196-202, 1988

22. Greensmith AL, Holmes AD, Lo P, Maxiner W, Heggie AA, Meara JG: Complete correction of severe scaphocephaly: the Melbourne method of total vault remodeling. Plast Reconstr Surg 121:1300-1310, 2008

23. Guimarães-Ferreira J, Gewalli F, David L, Olsson R, Friede H, Lauritzen CG: Spring-mediated cranioplasty compared with the modified pi-plasty for sagittal synostosis. Scand J Plast Reconstr Surg Hand Surg 37:208-215, 2003

24. Haas LL: Roentgenological skull measurements and their diagnostic applications. Am J Roentgenol Radium Ther Nucl Med 67:197-209, 1952

25. Inagaki T, Kyutoku S, Seno T, Kawaguchi T, Yamahara T, 
Oshige $\mathrm{H}$, et al: The intracranial pressure of the patients with mild form of craniosynostosis. Childs Nerv Syst 23:14551459,2007

26. Ingraham FD, Alexander E Jr, Matson DD: Clinical studies in craniosynostosis analysis of 50 cases and description of a method of surgical treatment. Surgery 24:518-541, 1948

27. Jane JA, Edgerton MT, Futrell JW, Park TS: Immediate correction of sagittal synostosis. J Neurosurg 49:705-710, 1978

28. Jimenez DF, Barone CM: Endoscopic craniectomy for early surgical correction of sagittal craniosynostosis. J Neurosurg 88:77-81, 1998

29. Jimenez DF, Barone CM, McGee ME, Cartwright CC, Baker CL: Endoscopy-assisted wide-vertex craniectomy, barrel stave osteotomies, and postoperative helmet molding therapy in the management of sagittal suture craniosynostosis. $\mathbf{J}$ Neurosurg 100 (5 Suppl Pediatrics):407-417, 2004

30. Kaiser G: Sagittal synostosis-its clinical significance and the results of three different methods of craniectomy. Childs Nerv Syst 4:223-230, 1988

31. Kandasamy J, Anderson K, Dunne J, Grogan J, Duncan C, Sinha A, et al: Treatment of scaphocephaly with combined vertex craniectomy and bilateral microbarrel staving. J Craniofac Surg 22:42-46, 2011

32. Khechoyan D, Schook C, Birgfeld CB, Khosla RK, Saltzman $\mathrm{B}$, Teng CC, et al: Changes in frontal morphology after single-stage open posterior-middle vault expansion for sagittal craniosynostosis. Plast Reconstr Surg 129:504-516, 2012

33. Lane LC: Pioneer craniectomy for the relief of mental imbecility due to premature sutural closure and microcephalus. JAMA 18:49-50, 1892

34. Lannelongue M: De la craniectomie dans la microcephalie. Compte Rendu Acad Sci 110:1382-1385, 1890

35. Lauritzen C, Sugawara Y, Kocabalkan O, Olsson R: Spring mediated dynamic craniofacial reshaping: case report. Scand J Plast Recons Surg Hand Surg 32:331-338, 1998

36. Marsh JL, Jenny A, Galic M, Picker S, Vannier MW: Surgical management of sagittal synostosis. A quantitative evaluation of two techniques. Neurosurg Clin N Am 2:629-640, 1991

37. Marucci DD, Johnston CP, Anslow P, Jayamohan J, Richards PG, Wilkie AO, et al: Implications of a vertex bulge following modified strip craniectomy for sagittal synostosis. Plast Reconstr Surg 122:217-224, 2008

38. Massimi L, Di Rocco C: Mini-invasive surgical technique for sagittal craniosynostosis. Childs Nerv Syst 28:1341-1345, 2012

39. Murray DJ, Kelleher MO, McGillivary A, Allcutt D, Earley MJ: Sagittal synostosis: a review of 53 cases of sagittal suturectomy in one unit. J Plast Reconstr Aesthet Surg 60:991-997, 2007

40. Mutchnick IS, Maugans TA: Nonendoscopic, minimally invasive calvarial vault remodeling without postoperative helmeting for sagittal synostosis. J Neurosurg Pediatr 9:222-227, 2012

41. Panchal J, Marsh JL, Park TS, Kaufman B, Pilgram T: Photographic assessment of head shape following sagittal synostosis surgery. Plast Reconstr Surg 103:1585-1591, 1999
42. Patel A: Population-level predictors of surgical techniques in 1,680 patients. Presented at the ISCFS XIV Biennial International Congress, 27 August-01 September, 2011, Livingstone, Zambia. Montreal: ISCFS, 2011 (Abstract)

43. Pawl RP, Sugar O: Zenker's solution in the surgical treatment of craniosynostosis. J Neurosurg 36:604-607, 1972

44. Proctor MR: Endoscopic cranial suture release for the treatment of craniosynostosis-is it the future? J Craniofac Surg 23:225-228, 2012

45. Renier D, Lajeunie E, Arnaud E, Marchac D: Management of craniosynostoses. Childs Nerv Syst 16:645-658, 2000

46. Ridgway EB, Berry-Candelario J, Grondin RT, Rogers GF, Proctor MR: The management of sagittal synostosis using endoscopic suturectomy and postoperative helmet therapy. J Neurosurg Pediatr 7:620-626, 2011

47. Roddi R, Vaandrager JM, Gilbert PM, van der Meulen JC: Reshaping of the skull in the early surgical correction of scaphocephaly. J Craniomaxillofac Surg 21:226-233, 1993

48. Rougerie J, Derome P, Anquez L: [Craniostenosis and craniofacial dysmorphism. Principles of a new method of treatment and its results.] Neurochirurgie 18:429-440, 1972 (Fr)

49. Simmons DR, Peyton WT: Premature closure of the cranial sutures. J Pediatr 31:528-547, 1947

50. Tessier P: [Total facial osteotomy. Crouzon's syndrome, Apert's syndrome: oxycephaly, scaphocephaly, turricephaly.] Ann Chir Plast 12:273-286, 1967 (Fr)

51. Toma R, Greensmith AL, Meara JG, Da Costa AC, Ellis LA, Willams SK, et al: Quantitative morphometric outcomes following the Melbourne method of total vault remodeling for scaphocephaly. J Craniofac Surg 21:637-643, 2010

52. van Veelen ML, Eelkman Rooda OH, de Jong T, Dammers R, van Adrichem LN, Mathijssen IM: Results of early surgery for sagittal suture synostosis: long-term follow-up and the occurrence of raised intracranial pressure. Childs Nerv Syst 29:997-1005, 2013

53. van Veelen ML, Mathijssen IM: Spring-assisted correction of sagittal suture synostosis. Childs Nerv Syst 28:1347-1351, 2012

54. Whitaker LA, Bartlett SP, Schut L, Bruce D: Craniosynostosis: an analysis of the timing, treatment, and complications in 164 consecutive patients. Plast Reconstr Surg 80:195-212, 1987

\section{Author Contributions}

Conception and design: van Veelen, van Adrichem, Mathijssen. Acquisition of data: van Veelen, Mihajlović. Analysis and interpretation of data: van Veelen. Drafting the article: van Veelen, Mihajlović. Critically revising the article: Dammers, Lingsma, van Adrichem, Mathijssen. Statistical analysis: Dammers, Lingsma. Study supervision: Mathijssen.

\section{Correspondence}

Marie-Lise C. van Veelen, Department of Neurosurgery, Erasmus University Medical Center Rotterdam, P.O. Box 2060, 3000 CB Rotterdam, The Netherlands. email: m.l.c.vanveelen@erasmusmc.nl. 